\title{
Aulas multiculturales y aulas de paz. Dos propuestas para un país en posconflicto ${ }^{1}$
}

\author{
Multicultural and peace classrooms. Two proposals for a post-conflict \\ country
}

Aulas muticulturais e aulas de paz. Duas propostas para um país em pósconflito

\author{
José Ignacio Bolaños Motta ${ }^{2}$ \\ Universidad de los Llanos, Colombia
}

Recepción: 28/11/2017

Evaluación: 05/01/2018

Aceptación: 29/06/2018

Artículo de Investigación - Revisión

DOI: $10.19053 / 01227238.8563$

“Lo que se está negociando en

La Habana son las armas, no son los conflictos (...) los conflictos sociales seguirán su curso". Alfredo Molano.

\section{RESUMEN}

En este artículo de reflexión se dimensionan algunos de los sentidos misionales de la educación colombiana a inicios del siglo xxI, no sin antes generar una reflexión histórica enfocada al ámbito de los fenómenos educativos, realizada desde una perspectiva histórico-crítica, acerca de la manera como se han construido formas de ciudadanía en el país. Lo anterior se ubica en la perspectiva, quizás utópica, de una cultura para la paz a partir de considerar los términos de una política de posconflicto. Asimismo, se intenta repensar el imaginario ciudadano desde una perspectiva histórica por medio de una indagación bibliográfica y documental, encontrándose dos propuestas en torno a la educación nacional: la primera consiste en que se ha de preparar a la escuela colombiana para realizar una propuesta de naturaleza multicultural. Y la segunda se postula desde el método como la condición multicultural ha de apuntalar una perspectiva de paz. Luego de presenta-

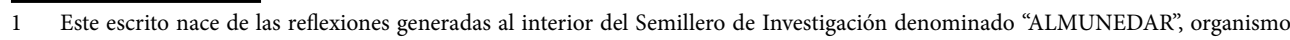
financiado por la Universidad de los Llanos desde el 2017.

2 Licenciado en música y Magíster de la Universidad del Cauca, actualmente se desempeña como docente e investigador en la Universidad de los Llanos en Villavicencio (Meta).Correo electrónico: jbolanos@unillanos.edu.co; ignaciomotta@unicauca.edu.co 
das estas ideas, se espera evidenciar que existe la posibilidad de unir las dos tendencias políticas de escuela colombiana, a modo de una sola propuesta por la cual, desde la comprensión de la diferencia, en diversas instituciones se propicien las habilidades sociales concernientes a la generación de una cultura para la paz.

Palabras clave: Paz; Revista Historia de la Educación Latinoamericana; educación; historia; escuela; multiculturalismo.

\footnotetext{
ABSTRACT

This reflection paper exposes some of the missionary senses of the Colombian education at the beginning of the 21st century. In the first instance, a historical and critical reflection on educational phenomena is carried out in order to understand the citizenship types built in the country. This is perhaps a utopian perspective of a culture for peace based on considering the terms of a post-conflict policy. According to the above, we attempt to rethink the citizen's imaginary from a historical perspective by means of a bibliographic and documentary inquiry, from which two proposals regarding the national education emerge: the first one claims that the Colombian school must be prepared to make a proposal of multicultural nature. The second one, postulated from the method, as the multicultural condition that must reaffirm a perspective of peace. With the presentation of these ideas, we hope to evidence the possibility of joining the two political tendencies of the Colombian school in a single proposal that, from the understanding of the difference, foster the social skills necessary for the generation of a peace culture.
}

Keywords: Peace; Journal History of Latin American Education; education; history; school; multiculturalism

\section{RESUMO}

Neste artigo de reflexão se dimensionam alguns dos sentidos missionários da educação colombiana em inícios do século XXI, não sem antes gerar uma reflexão histórica focada no âmbito dos fenômenos educativos, realizada a partir de uma perspectiva histórico-crítica sobre a maneira como foram construídas formas de cidadania no país. Isto está localizado em uma perspectiva, talvez utópica, de uma cultura para a paz a partir do que se considera o fim de uma política pós-conflito. Assim mesmo, objetiva repensar o imaginário cidadão desde uma perspectiva histórica por meio de uma indagação bibliográfica e documental, encontrando-se duas propostas em torno da educação nacional: a primeira consiste em que se há de preparar a escola colombiana para realizar uma proposta de natureza multicultural. E a segunda se postula desde como o método como a condição multicultural deverá sustentar uma perspectiva de paz. Logo que apresentadas estas ideias, se espera evidenciar que existe a possibilidade de unir as tendências políticas da escola colombiana, através de uma única proposta por meio da qual, desde a compreensão da diferença, em diversas instituições se desenvolvam as habilidades sociais concernentes à geração de uma cultura para a paz.

Palavras-chave: Paz; Revista História da Educação Latino-americana; educação; história; escola; multiculturalismo.

\section{INTRODUCCIÓN}

América Latina ha sufrido a lo largo de su historia una serie de problemáticas sociales, muchas de ellas ligadas al periodo colonial cuyas huellas - a pesar del paso de los siglos - aún no se desvanecen; todavía se perciben en la cultura 
moderna las improntas de una sociedad y un pensamiento colonial ${ }^{3}$. Lo colonial permeó a su vez la escuela nacional durante las primeras décadas de la República, si bien: "La escuela era definitivamente un fenómeno de élites y el número de estudiantes por colegio era muy reducido. Además se encontraban ubicadas solo en las ciudades y villas donde vivían los españoles" ${ }^{4}$. De esta manera se fueron generando los conflictos en donde se afirmaron la segregación y la exclusión sociales que aún hoy continúan afectando las formas de autoestimarse y de asumir al otro; todo lo cual se halla presente en los múltiples escenarios educativos y ha contribuido a desarrollar una cultura violenta, sintomática, que se espera solucionar en el siglo xxI.

\section{Los orígenes}

A partir de un violento proceso de mestizaje ${ }^{5}$, durante las épocas de la Colonia y la primera República, hasta la consolidación del Estado-nación, en Colombia se generaron una serie de divisiones sociales a las cuales no se les ha dado una solución definitiva. Estas divisiones, que en un principio se referían a aspectos de orden cultural y económico, dieron lugar a un tipo de violencia política ${ }^{6}$ que aún no ha logrado ser subsanada. Luego de este proceso de mestizaje y posterior liberación de la colonia española, las prácticas discriminatorias se fueron matizando con el advenimiento de los nuevos gobiernos del nuevo Estado nacional; sin embargo, la condición de una cultura multiétnica, orientada a estimar las problemáticas de aceptación del otro en términos de diferencia, ha tenido soluciones de carácter parcial. Lo anterior se evidencia en las prácticas culturales violentas presentes en los más variados sectores del territorio colombiano, país que ha llegado a calificarse como uno de los más violentos de Occidente ${ }^{7}$, y en el que se observa que no existe una formación para la paz, pues se cree que la paz proviene unívocamente del diálogo o el acuerdo pactado entre los grupos alzados en armas y el Gobierno nacional.

De otro lado, y más allá de las negociaciones realizadas para el marco del acuerdo de paz en La Habana, Cuba, la escuela colombiana se encuentra ante el reto de proponer el desarrollo de una cultura para la paz. En el ámbito educativo, esta propuesta se sustenta en dos espacios de trabajo: las aulas multiculturales y las aulas de paz. Se espera entonces que a partir de estos dos escenarios, posiblemente desarrollados de forma paralela en las aulas nacionales, se haga realidad la utopía de una cultura para la paz, al seno de una escuela que dimensione e incorpore esta perspectiva como una de sus metas misionales.

3 Catherine Walsh, ed., Pedagogías decoloniales. Prácticas insurgentes de resistir, (re)existir y (re)vivir (Quito: Abya-Yala, 2013 ), 25.

4 Alberto Martínez, Dos estudios sobre la educación en la Colonia (Bogotá: Centro de Investigaciones Universidad Pedagógica Nacional (CIUP), 1984), 15.

5 Carmen Bernand, "Identificaciones: músicas mestizas, músicas populares y contracultura en América (siglos xVI-XIx)", Historia Crítica, n. ${ }^{\circ}$ 54. (Bogotá: Universidad de los Andes, 2014): 30.

6 Humberto Maturana et al., Violencia. En sus distintos ámbitos de expresión (Santiago: Dolmen Ediciones, 2000), 70.

7 Estanislao Zuleta, Colombia: violencia, democracia y derechos humanos (Bogotá: Ariel, 2015), 139. 


\section{Colombia como varios pueblos y como uno solo}

Variedad de pueblos han migrado a Colombia desde sus inicios como Estado-nación hasta hoy, entre otros, colonos españoles, gitanos ${ }^{8}$, judíos sefardíes, población árabe del disuelto imperio turco otomano, como también africanos que, esclavizados, arribaron al país durante la colonia española ${ }^{9}$, cuyos afrodescendientes apenas ahora se encuentran en proceso de etnización ${ }^{10}$. Aunque los pueblos mencionados han llegado al país de diferentes maneras, los pobladores del Estado nacional colombiano han sido, en sus representaciones más amplias, indígenas, grupos afrodescendientes y población mestiza. La pregunta que surge para los propósitos de este escrito es: ¿en los tiempos de la Gran Colombia se pensó en una educación para la convivencia y para la heterogeneidad de los pueblos que en ella habitaban?

La respuesta es, por lo pronto, evidentemente negativa. Es tan notable la precariedad del respeto hacia el otro y su cultura en la educación colombiana, que los ejemplos de esta violencia, en términos del pensamiento y de las prácticas, abundan en las bibliotecas. Y para ejemplificar un poco, el autor del presente escrito conoció, a través de un seminario de maestría en estudios multiculturales, que a los padres de una mujer indígena del departamento del Cauca, un grupo de monjas les depositaban ceniza caliente en la boca tan pronto como los escuchaban hablando en su propia lengua, pues el objetivo misional de las religiosas era que aprendieran el idioma castellano para que pudiesen leer la Biblia y " $c i$ vilizarse" a través de la religión cristiana ${ }^{11}$. De modo que, si este es el trato que se les otorga a los pueblos aborígenes, el trato dado a los grupos migrantes no distaba mucho de la misma perspectiva colonial. Cualquier individuo que perteneciera a esos grupos humanos traídos a la fuerza al territorio hoy conocido como Colombia, no esperaba ser parte de una nueva nación que lo denominase ciudadano. Los pocos que conservaron una idea de su origen la perdieron a causa de la violencia física o epistémica ${ }^{12}$, pues si alguno de los grupos nativos o migrantes tenían una forma de vivir y de dimensionar su cultura, debieron habituarse a una nueva propuesta de nación. Sin embargo, hoy en día todas estas personas son parte de un nosotros denominado en el ámbito del Estado nación como el pueblo colombiano. $\mathrm{Y}$ al no existir un discurso multicultural reconocido en la geografía nacional, la población mestiza en el poder negó muchos de los sectores otros del territorio nacional; negación que tuvo vigencia en las constitu-

8 Ana Gómez, Pueblo Rrom -Gitano-de Colombia: haciendo camino al andar (Bogotá: Departamento Nacional de Planeación (DNP), 2010), 14.

9 Jorge Rangel, “Etnización en La Boquilla (Cartagena- Colombia) (Bogotá: Pontificia Universidad Javeriana, 2015), 12.

10 Eduardo Restrepo, "Etnización de la Negridad”, en Genealogías de la colombianidad (Bogotá: Editorial Pontificia Universidad Javeriana, 2008), 96.

11 Jorge Enrique Duarte Acero y Martha Consuelo Riveros Bonilla, "El Uso del Catecismo en la Enseñanza de la Religión Católica en el Periodo Neogranadino y de los Estados Unidos de Colombia 1831-1886”, en Revista de la Educación. no. 16 (2011): 126.

12 Santiago Castro, "Ciencias sociales, violencia epistémica y el problema de la invención del otro", en La colonialidad del saber: eurocentrismo y ciencias sociales. Perspectivas latinoamericanas (Buenos Aires: Consejo Latinoamericano de Ciencias Sociales (CLACSO), 2000), 91. 
yentes nacionales durante muchos años. Este fenómeno fue visible en la legislación nacional, si bien excluía de manera directa a la población afrodescendiente ${ }^{13}$ dentro de una institucionalidad colombiana que consideraba al indígena como un menor de edad y era visto, desde los estudios hechos por Rojas y Castillo, como alguien a quien se le debía culturizar. En este mismo sentido, Germán Colmenares relata que la escuela nacional visualizaba a los grupos indígenas como un grupo humano al cual se le debía castellanizar, ya que:

Ahora, la lengua castellana debería servir como vínculo de integración y uniformidad del territorio, para que se disipara esa extensa zona incierta que existía entre la Gobernación de Popayán y el resto del Nuevo Reino, que "era una verdadera frontera interior en la que resistieron durante mucho tiempo Paeces y Pijaos"14.

Y también cristianizar:

Esa falta de maestro y de escuelas las suplían en parte los párrocos que acogían en la casa cural a niños y jóvenes de buenas capacidades y aprobada virtud, a quien la familia deseaba hacerle eclesiástico y les enseñaba un poco de latín, amén un tanto de los demás conocimientos esenciales al sacerdote... hasta dejarlos en estado de aspirar a las órdenes sagradas ${ }^{15}$.

Las diferencias de clase, condición étnica o credo religioso han echado raíz en el plano de la opinión pública, si bien las noticias nacionales de principios de siglo dejan ver el alto grado de injusticia social presente por entonces en el territorio colombiano. Estos fenómenos, cubiertos por un velo de cierta normalidad, y dado que no han sido asumidos o reflexionados por la escuela colombiana, tampoco han sido vistos en replay por el común de la gente. En efecto, estas inequidades han sido invisibilizadas con el objetivo de ponderar ciertos aspectos que se han asumido como más importantes, a modo de estimar el desarrollo de civiles laicos o ilustrados. Se asume, entonces, que resulta muy complejo formar una cultura de paz ${ }^{16}$ o para la paz, pues aquella utopía aún no existe en el imaginario colombiano; en otras palabras: todavía persiste el deseo de ganarles la guerra a los grupos insurgentes desde un modelo de paz basado en la postvictoria $^{17}$, y no existe una propuesta tal de unidad nacional construida a partir de la visualización de las diferencias, como tampoco parece existir una praxis social para el reconocimiento de las diferencias. En otras palabras, las leyes contemplan el reconocimiento pero la sociedad aún no. Esto ocurre en la medida en que

13 Elizabeth Castillo y Axel Rojas, Educar a los otros. Estado, políticas educativas y diferencia cultural en Colombia (Popayán: Universidad del Cauca, 2005), 19.

14 Germán Colmenares, Historia económica y social de Colombia (Bogotá: Instituto Nacional de Cultura, 1979), 310.

15 Danilo Nieto, La educación en el Nuevo Reino de Granada (Bogotá: Ediciones Santa Fe, 1955), 74.

16 José Tuvilla, "Cultura de paz y educación para la ciudadanía democrática" (jornadas de cooperación educativa con Iberoamérica sobre educación y cultura para la paz, Cartagena, 20 al 24 de noviembre de 2006), http://www.aecidcf.org.co/documentos/MI\%20 11.669.pdf

17 Ariel Ávila, “Los 50 años de guerra podrían ser el último cumpleaños", Semana, n. ${ }^{\circ} 1778$ (mayo 2014). 
el ciudadano no reconoce ser parte de un país diverso, ya que prevalece el deseo de una mayoría de imponerse sobre una minoría; mayoría normalizada a la que cada ciudadano espera pertenecer. Un ejemplo ayuda a vislumbrar la magnitud del problema esbozado. Estados Unidos, a partir de las luchas civiles generadas en los años setentas, dio un trato distinto a estos fenómenos culturales ya que se planteó una unidad nacional a partir de una política multicultural, luego de que las banderas de los derechos civiles así lo reclamaban ${ }^{18}$. Por su parte, Colombia no ha hecho un proceso detenido hasta ahora en cuanto a políticas de reconocimiento se refiere, pues si bien la Constitución de 1991 sí lo expresa, la realidad no lo evidencia. Y aunque para muchos académicos es inviable una paz sin justicia social ${ }^{19} \mathrm{y}$ sin las garantías de un Estado moderno de bienestar ${ }^{20}$, el Estado colombiano, a partir de las políticas ejercidas por Juan Manuel Santos desde el año 2010, ha alcanzado un acuerdo de paz con el grupo insurgente de las FARC, hoy reconvertido en grupo político, a través de la denominada mesa de conversaciones. Esta propuesta está permeada de la visión de un mejoramiento para la nación a partir de los beneficios que esta nueva situación espera desarrollar a través de la inversión extranjera, sobre un país en paz.

No obstante, dimensionar la educación para el posconflicto como una elaboración cultural para reconocer la dejación de las armas en un momento de la historia es una dimensión insuficiente, pues el conflicto no se encuentra unívocamente en "las montañas de Colombia", el conflicto se halla en esta cultura (violenta, excluyente, clasista y colonial) que se ha hecho cotidiana en la sociedad colombiana. Es por esto que una política para el posconflicto ha de forjarse desde ámbitos diversos, como pueden llegar a ser las políticas para la equidad, los programas de gobierno, los medios de comunicación, las políticas estratégicas para la protección al ciudadano y, muy particularmente, desde los fenómenos educativos inclusivos, ámbito para el cual fue escrito el presente artículo.

\section{Recapitulación histórica}

En el plano histórico resulta escasa la reflexión en torno a la convivencia sobre la diferencia, en lo que respecta a una propuesta educativa dentro de las instituciones educativas colombianas. A principios del siglo pasado, el sistema clerical, a cargo de la educación nacional, importó al país el modelo lancasteria$n^{21}$ heredado de la visión protestante estadounidense. Años después y avanzando a grandes pasos, bajo la propuesta de los estados liberales, se fundó una educación laica orientada a la enseñanza de las ciencias y desde el ideal de Es-

18 Delfín Grueso, “¿Qué es el multiculturalismo?”, El Hombre y la Máquina, n. $20-21$ (Cali: Universidad Autónoma de Occidente, 2003): 17.

19 François Dubet, Repensar la justicia social. Contra el mito de la igualdad de oportunidades (Madrid: Siglo XXI editores, 2010 ), 114.

20 Adela Cortina, Ciudadanos del mundo. Hacia una teoría de la ciudadanía (Madrid: Alianza Editorial, 2009), 59.

21 Queipo Timaná, “¿Por qué y sobre qué debemos investigar en pedagogía en Colombia?”, Praxis y Saber, n. 1 (Tunja: UPTC, 2009): 252. 
tado nacional, liberal y laico ${ }^{22}$. Ya hacia la segunda mitad del siglo $\mathrm{xx}$, con motivo del modelo colonial americano y desde la política del plan América para el mundo, Latinoamérica entró a ser parte del plan Marshall. Esto generó cambios sustanciales en lo que al funcionamiento de las instituciones ${ }^{23}$ escolares se refiere, pues el dominio lo ejerció el modelo desarrollista del pensamiento imperial ${ }^{24}$ estadounidense, adoptado a los términos de la educación nacional, cuyo modelo se encaminó a modernizar el Estado nacional colombiano. Durante este periodo la escuela nacional dimensionó al estudiante como un ciudadano normalizado y útil para el trabajo en las grandes ciudades; posición que no sufrió variaciones significativas en la Constitución de 1991. Así, desde la Asamblea Nacional Constituyente hasta nuestros días, ha habido una convivencia entre los distintos modelos de escuela nacional, entre los que se cuentan: los colegios confesionales, las escuelas liberales y los modelos escolares nacidos a partir del modelo de la escuela nueva; modelos que no poseen diferencias de fondo $y$, en términos del mundo globalizado, evidencian un distanciamiento entre una educación para la paz y las propuestas realizadas por el Estado para las escuelas nacionales ${ }^{25}$.

En los últimos años las luchas por los derechos de las minorías han generado nuevos interrogantes, como por ejemplo: ¿Cómo se está formando para la paz en las escuelas?, o ¿qué modelo de escuela se está formulando para el posconflicto? Pues dentro de la perspectiva del reconocimiento ante la nación, existen aún hoy sectores que reclaman un espacio en la escuela; sectores entre los que se encuentran las poblaciones marginales ${ }^{26}$, los grupos indígenas, la población Rrom ${ }^{27}$, los desplazados por la violencia y la población afrocolombiana. A estos grupos se suman ahora los desmovilizados de la guerrilla y los grupos paramilitares, grupos que necesitan del apoyo de los colombianos para entrar a ser parte de la vida civil, y para lo cual es preciso pensar en una escuela para la paz y con una perspectiva a largo plazo. Todos los grupos mencionados problematizan (también positivamente) la escuela colombiana y sus alteridades, hecho que requiere que se genere una resignificación de la política multicultural a partir de aulas en donde se les reconozca como actores y miembros activos de la sociedad, dejando atrás el pasado y permitiendo un estado de perdón ${ }^{28}$ por parte de la sociedad, lo cual resulta ser una de las necesidades más complejas, tanto para la sociedad colombiana en general, como para su respectivo sistema educativo.

22 Óscar Saldarriaga, Del oficio de maestro. Prácticas y teorías de la pedagogía moderna en Colombia (Bogotá: Cooperativa Editorial Magisterio, 2003), 15

23 José Bolaños Motta, "La educación en Colombia. Una mirada al tiempo, espacio y pensamiento curricular desde las guías didácticas para maestros de escuela primaria”, en Magnolia Aristizábal (comp.), Traslapamiento de la pedagogía por el currículo: Colombia 19601975 (Popayán: Editorial Universidad del Cauca, 2011), 171.

24 Jaime Fayad Herrera, "Del planeamiento educativo al currículum: un pensamiento imperial", en Traslapamiento de la pedagogía..., ibíd., 48.

25 Este hecho reviste gran complejidad pues resulta apenas improbable obtener un resultado académico satisfactorio en las pruebas Pisa para un adolescente que se encuentra ante un contexto violento por definición cultural.

26 Loïc Wacquant, Parias urbanos. Marginalidad en la ciudad a comienzos del milenio (Buenos Aires: Manantial, 2001), 86.

27 Ana Gómez, op. cit.

28 Antanas Mockus, “¿Para qué el perdón?”, Theologica Xaveriana, n. ${ }^{\circ} 141$ (2002): 47-60. 


\section{Las leyes del Estado nacional y la escuela}

La violencia física y epistémica ${ }^{29}$ que históricamente se ha impuesto sobre las minorías ha desarrollado un estigma social ${ }^{30}$ sobre muchos grupos, hecho que ha generado marcas muy fuertes en el imaginario del país. Si bien es verdad que resulta complejo determinar las causas por las cuales un país se hace violento, la escuela colombiana no ha asumido un camino en la perspectiva de construir una sociedad pacífica. En tal sentido, es responsabilidad de la política educativa nacional no haber pensado "las formas de hacer escuela" ${ }^{11}$ como un laboratorio de paz. De no ser así, por ejemplo, ¿dónde están los programas para el desarrollo de la cultura de la paz en las cartillas didácticas ${ }^{32}$ de los años setentas? La respuesta es que, mientras estos programas no existen o no están expuestos de forma vehemente, lo que sí se observa es una escuela homogeneizante ${ }^{33}$, hecho que aún hoy adquiere vigencia, más todavía durante el periodo desarrollista de la nación y de la educación ${ }^{34}$, si bien en esta etapa la educación estuvo centrada en la formación de buenos ciudadanos ${ }^{35}$, aptos para una cultura citadina de un país consumista. Toda esta realidad pervive hasta los primeros años del siglo XXI, aunque las políticas educativas persistan en favorecer al colombiano otro ${ }^{36}$ en los últimos años.

Así, el no reconocimiento del otro en el ámbito de la legalidad y de la educación, formó divisiones en el imaginario colombiano, generando divisiones que, en términos de clase, fenotipo y religión, fundamentaron los imaginarios en torno a la diferencia. Y el debilitamiento del nosotros en al ámbito de lo comunal o comunitario dio como resultado la creación y la sobredimensión de un yoísmo regional.

\section{Aulas multiculturales}

Aunque pareciese que el Estado-nación mantuviera en sí mismo la idea de la homogenización, el mismo Estado también se puede fundamentar bajo un ideal multi-identitario, percibido desde el visionamiento de un país pluriétnico y multicultural ${ }^{37}$. No obstante, esta afirmación no ha adquirido dimensiones sociales trascendentales hasta ahora, pues en el momento de representar o atender

\footnotetext{
29 Castro, op. cit.

30 Erving Goffman, Estigma. La identidad deteriorada (Madrid: Amorrortu Editores, 2006), 11.

31 María del Pilar Unda Bernal y Alba Nelly Gutiérrez Calvo, "Viajes y encuentros pedagógicos como experiencias de formación de maestros” Nodos y Nudos. volumen 4 N. ${ }^{\circ}$ 39. (Bogotá: Universidad Pedagógica Nacional, 2015): 9.

32 Bolaños, op. cit.

33 Alberto Martínez, "De la escuela expansiva a la escuela competitiva: Dos modos de modernización en América Latina", Reseñas Educativas, n. ${ }^{\circ} 90$ (2005): 4.

34 Magnolia Aristizábal, María Eugenia Muñoz y Carlos Tosse, "El gigante en el país de los liliputienses: Las ilusiones del desarrollo y el planeamiento para la educación”, en Traslapamiento de la pedagogía..., op. cit., 47.

35 Bolaños, op. cit.

36 Elizabeth Castillo y Axel Rojas, op. cit., 53.

37 Charles Taylor, El multiculturalismo y "la política del reconocimiento" (México: Fondo de Cultura Económica, 2010), 26.
} 
a las alteridades, existen sectores de la nación que se encuentran reclamando espacios dentro de la sociedad colombiana, o por fuera de ella. Se trataría entonces de encontrar puntos de convergencia, más allá de un sentir romántico por los símbolos patrios. Para ejemplificar un poco el asunto, muchos grupos indígenas poseen sistemas curriculares que los hacen incompetentes ante el sistema universitario estatal, además de no poseer sistemas universitarios ${ }^{38}$ planteados desde su cultura y para su cultura. Esto es un dilema que aún no ha encontrado solución pues prevalece la propuesta del conocimiento blanqueado y occidental que muchos indígenas se niegan a admitir como un saber para el vivir. Esta problemática se evidencia a partir de las relaciones de tensión para con el mundo mestizo.

Por otro lado, la historia de los afroamericanos ${ }^{39}$ o afrodescendientes no es más grata que la anterior, mucho menos en los términos de una cultura para el reconocimiento social. Quizás a esto se deba que la historia nacional enuncia que: “La población negra, mientras tanto, permanecía excluida de las nacientes representaciones de la nación, no siendo incorporada en su iconografía y manteniendo hasta mediados de siglo su condición jurídica de esclavizadas" ${ }^{40}$. Finalmente, las minorías sexuales aún no han alcanzado un estatus de reconocimiento social, pues se mantienen afectadas por la discriminación y, en algunos casos, por el matoneo de una sociedad que se niega a aceptar su contra-natura, hecho que se distancia de las dimensiones de un mundo pluralista y de derechos, si bien:

Research shows that sexual and gender-based bullying affects any learners perceived as not conforming to prevailing sexual and gender norms, including those who are lesbian, gay, bisexual, transgender or intersex. This specific type of bullying, referred to as homophobic bullying, has serious repercussions for education. (...) The Secretary-General described homophobic bullying as a "moral outrage, a grave violation of human rights. ${ }^{41}$

Asimismo, pensado desde la óptica del bienestar ${ }^{42}$, Colombia, como Estado nacional, debería garantizar que sus políticas educativas respeten la diversidad cultural de las distintas comunidades. En este sentido se dice que:

Los gobiernos y la sociedad civil deben colaborar de manera concertada para promover la educación primaria universal del grueso de la población y potenciar su

38 Diana Elvira Soto Arango, José Antonio Rivadeneira, Jorge Enrique Duarte Acero, Sandra Liliana Bernal Villate, "La generación del movimiento estudiantil en Colombia. 1910-19241”, Revista Historia de la Educación Vol. 20 no. 30 (2018): 225.

39 Manuel Zapata Olivella, Changó, el Gran Putas (Bogotá: Ministerio de Cultura de Colombia, 2010), 633.

40 Elizabeth Castillo y Axel Rojas, op. cit., 31.

41 Las investigaciones muestran que el acoso sexual y de género afectan a algunos estudiantes, quienes perciben que no hacen parte de las normas que prevalecen como mayoría sexual, esto incluye a lesbianas, homosexuales, bisexuales, transexuales o intersexuales. Este tipo específico de acoso escolar, conocido como matoneo homofóbico, tiene graves repercusiones en el ámbito educativo. (...) El Secretario General describió el acoso a los homosexuales como un "ultraje moral y una grave violación a los derechos humanos". (Traducción mía). Education sector responses to homophobic bullying (París: Unesco, 2012), 12.

42 Cortina, op. cit. 
arraigo en las comunidades, y el entendimiento de los grandes beneficios para todos los miembros de la sociedad de unos mejores resultados de educación y desarrollo de los grupos marginados ${ }^{43}$.

$\mathrm{Al}$ respecto, si bien resulta difícil para un Estado tener a toda su población satisfecha, también se ha de sopesar que Colombia es un Estado de derecho, en el cual sus ciudadanos contribuyen a la nación con el objetivo de ser reconocidos como parte de la misma. No obstante, se advierte que buena parte de la ciudadanía nacional se encuentra aún por fuera del reconocimiento del Estado-nación, hecho que demanda una política social de reconocimiento. En el presente escrito se intenta objetar que este reconocimiento proviene en gran medida de la escuela.

Partimos entonces de la idea que piensa la complejidad del multiculturalismo como práctica social y política, ya que multiculturalismo significa en su acepción básica muchas culturas $^{44}$. Es por esta razón que en la actualidad vivimos en una sociedad multicultural generada directamente de una modernidad globalizante e incluyente. En este mismo plano de ideas y contextos nos encontramos ante un país de aulas multiculturales, para las cuales los docentes aún no están lo suficientemente formados en lo académico ni en lo humanístico. Podríamos decir que dentro de las tres clases de multiculturalismo (el liberal, el pluralista y el comunitarista ${ }^{45}$ ) es posible plantear como posibilidad para la realidad colombiana un multiculturalismo comunitarista, en el cual se logre ver a la gran comunidad como garante de cada uno de los sujetos que la componen. En otras palabras, un sujeto comunitario consiente de su actuar consigo mismo y con la sociedad. En tal sentido, el multiculturalismo propende por una libertad individual y, por los compromisos sociales, comunal; por esta razón es que este sistema está enfocado hacia una educación autónoma o autogestiva, y se orienta a la superación de las inequidades ${ }^{46}$ a través de los consensos.

De otro lado, prevalecen en España y Latinoamérica otras visiones en la discusión por el ser de la cultura en las sociedades occidentalizadas, si bien se hace referencia a la interculturalidad como política de reconocimiento y a modo de perspectiva e imaginario para la educación ${ }^{47}$; perspectiva que en su acepción más simple significa entre-culturas, aun cuando no es solo este su significado, pues:

(...) no simplemente un contacto entre culturas, sino un intercambio que se establece en términos equitativos, en condiciones de igualdad. Además de ser una meta por alcanzar, la interculturalidad debería ser entendida como un proceso permanente de relación, comunicación y aprendizaje entre personas, grupos,

\footnotetext{
43 Unesco, "La educación para todos, 2000-2015: logros y desafíos" (París: Ediciones Unesco, 2015), 125.

44 Ernesto Díaz, "Multiculturalismo y educación", Cultura y representaciones sociales, n. 7 (2009): 31.

45 Ibíd., 44.

46 Ibíd., 50.

47 Rafael Sáez, “La educación intercultural”, Revista de Educación, n. 339 (2006): 859.
} 
conocimientos, valores y tradiciones distintas, orientada a generar, construir y propiciar un respeto mutuo, y a un desarrollo pleno de las capacidades de los individuos, por encima de sus diferencias culturales y sociales ${ }^{48}$.

No obstante, el Estado colombiano, desde la óptica de los derechos diferen$\operatorname{ciados}^{49}$, ha optado por una solución de corte multiculturalista ${ }^{50}$; hecho que se ha venido ratificando desde la Constitución de 1991 y su correspondiente Ley 115, hasta nuestros días. Aunque es de anotar que este discurso para el reconocimiento resulta ser a todas luces un modelo importado desde las perspectivas del Norte. En términos de su desarrollo, el multiculturalismo se gestó dentro de los ideales de nación de los Estados Unidos, pues ese país, a diferencia de Colombia, sí fue concebido para pensar la diferencia desde un principio, como también para la multiplicidad y para la alteridad ${ }^{51}$. En tal sentido, se podría decir que pensar al otro, contrario a pensarse sobre el otro, fue quizás uno de los sueños de ese Estado-nación.

Al respecto de este fenómeno, Charles Taylor define al multiculturalismo como la política del reconocimiento ${ }^{52}$, ello indica que se debieran incluir o insertar distintas culturas a un modelo educativo desde los términos del diálogo, la deliberación y los valores básicos de la democracia. De modo que, en caso de existir una discordancia: "Los colegios y las universidades pueden servir como modelos para la deliberación al fomentar la discusión intelectual rigurosa, franca, abierta e intensa, dentro o fuera de las aulas" 53.

Ahora bien, en la visión de un Estado moderno y participativo, la Asamblea Nacional Constituyente colombiana que se desarrolló a finales del siglo xx, fue un factor que determinó uno de los actos más decisivos de la historia del país, pues desde los tiempos de la Nueva Granada no existía una política definida hacia la diversidad étnica, lingüística o religiosa, o hacia el reconocimiento de un país multicultural. Es de esta manera como el multiculturalismo se convierte en "aquella ideología o modelo de organización social que afirma la posibilidad de convivir armoniosamente en sociedad entre aquellos grupos o comunidades étnicas que son cultural, religiosa o lingüísticamente diferentes" ${ }^{24}$. No obstante, y como se ejemplificó en páginas anteriores, en nuestro país y en planos históricos, la homogeneidad que ha primado en las aulas ha generado una política educativa asimilacionista, lo cual, en palabras de Aurora Marco, indica que esta política, hacia la educación, "(...)Tiende a eliminar las diferencias al escolarizar a todo el alumnado con el currículum de la cultura mayoritaria; así, los niños de culturas

\footnotetext{
48 Catherine Walsh, La Interculturalidad en la Educación (Lima: Ministerio de Educación / Unicef, 2005), 8.

49 Héctor Moreno, "Estado multicultural y derechos diferenciados en Colombia", Criterio Libre Jurídico, 8, n. ${ }^{\circ} 1$ (2011): 10.

50 Mónica Herrera, "Los retos del Estado multicultural en materia de paz", Semana, n. ${ }^{\circ} 1777$ (junio de 2013): 1.

51 Clifford Geertz, Los usos de la diversidad (Barcelona: Paidós, 1996), 122.

52 Delfín Grueso, op. cit., 18.

53 Charles Taylor, op. cit., 42.

54 Albert Jacquard, "Multiculturalidad", Olympus, n. ${ }^{\circ} 1$ (marzo de 2003): 2.
} 
diversas adoptan forzosamente la cultura del país receptor, infravalorando sus diferencias culturales y lingüísticas" ${ }^{\prime 55}$.

Una vez cuestionado este sistema curricular, se ha llegado a conclusiones muy críticas, donde se advierte que: "Muchos de los aspectos propios del currículum, su teoría y práctica han estado dirigidos más por presiones socioculturales externas y políticas que por análisis sistemáticos internos que den cuenta de lo que realmente ocurre en las escuelas pues muchas veces el currículo: selecciona, pondera y oculta"56. De tal suerte la constituyente colombiana terminó por definir que la nación colombiana era evidentemente multicultural, sin bien las políticas destinadas a la educación nacional continuaron siendo homogeneizantes, caso típico quizás de la cultura occidental, en donde el discurso se suele encontrar alejado u opuesto a las prácticas de vida.

\section{Las aulas de paz}

De manera independiente al hecho que el Estado colombiano haya pactado la dejación de las armas con los grupos armados, es evidente que la violencia en Colombia no es un factor que compete directamente a los actores políticos insurgentes o institucionales; la violencia en Colombia es una cuestión cultural, al igual que la corrupción en las entidades del Gobierno, entre otros problemas igualmente frecuentes. $\mathrm{Al}$ respecto, la mayor parte de la violencia colombiana ocurre por fuera del enfrentamiento político armado, aunque sí es a éste al que se le hace más énfasis, cuando se trata de hablar de violencia en el país. Las investigaciones de Enrique Chaux señalan: "Algunos estimativos indican que menos del $20 \%$ de los homicidios ocurren en combate o tienen una motivación política clara. No obstante al mayoría de estudios académicos sobre violencia colombiana se han concentrado en el nivel macro, en particular en el conflicto entre guerrilla, paramilitares y las fuerzas armadas" ${ }^{\prime \prime}$.

A razón de una política para el posconflicto, se ha venido hablando en Colombia de aulas de paz o aulas para la paz, pues se hace evidente que ante los problemas socioculturales enunciados en el presente escrito, el sistema educativo nacional no solo ha de estar pensado desde las competencias (comunicativas, matemáticas, deportivas, artísticas, y de más), puesto que, aparte de lo anterior, el colombiano necesita desarrollar competencias para la paz, con el fin de lograr vivir en sociedad. En otros términos, se necesitan ciudadanos $^{58}$ de concordancia para con una sociedad de respeto. Si bien este fenómeno se debería haber planteado hace muchos años, cuenta el dicho popular de "más vale tarde que nunca", pues en este momento sería mucho peor mantener un conflicto interno y eterno a causa de la ausencia de una reflexión sobre la utopía de la paz.

\footnotetext{
55 Aurora Marco, "Multiculturalismo y educación", Puertas a la lectura, n. ${ }^{\circ}$ 9-10. (2000): 3.

56 Rolando Poblete, "Multiculturalismo y educación”, Revista latinoamericana de educación inclusiva, n. 3 (2005): 184.

57 Enrique Chaux, "Buscando pistas para prevenir la violencia urbana en Colombia: Conflictos y agresión entre niños(as) y adolescentes en Bogotá", Revista de Estudios Sociales, n. ${ }^{\circ} 12$ (2002): 43.

58 Adela Cortina, op. cit., 25.
} 
Desde la educación, y para sí misma, en Colombia ha hecho falta una política clara y definida hacia la paz dirigida a las escuelas nacionales. Dado que la negociación con los grupos insurgentes no garantiza la cuestión de la paz en el país, se ha de hacer una gestión dirigida al aula escolar para el control de aspectos humanos como la ira, el acoso, la provocación, el matoneo y de cada uno de ellos, sus derivados o consecuencias, si bien, como hemos señalado, la violencia no es propiedad de los grupos paramilitares o guerrilleros. En otras palabras, la guerra no se encuentra únicamente en el monte, la guerra se encuentra en lugares tan convencionales como el hogar, o en los encuentros entre pandillas que apoyan a un equipo de fútbol, las peleas clandestinas de perros, las peleas entre ebrios, la violencia escolar, en el programa de humor de los sábados, o digamos más bien, en la normalidad y la praxis de muchas relaciones humanas. Con el propósito de ejemplificar algunas competencias para la paz, a continuación se cita a Chaux, Lleras y Velásquez, en torno a una posible didáctica desde las competencias para la paz:

1) manejo de la ira; 2) empatía, 3) toma de perspectiva; 4) generación creativa de opciones; 5) consideración de consecuencias; 6) escucha activa; 7) asertividad; y 8) cuestionamiento de creencias. (...) El manejo de la ira depende en gran medida de la competencia de reconocer y nombrar la ira en uno mismo. Esto supone poder identificar los signos corporales asociados con esta emoción, saber diferenciar los distintos niveles de intensidad que puede tener mi ira y saber reconocer las situaciones que usualmente generan ira en $\mathrm{mi}^{59}$

De no prospectar la niñez hacia la creación de una ciudadanía proactiva de la paz, es muy posible que una vez alcancen la adultez, las nuevas generaciones de colombianos se vean enfrentadas a situaciones riesgosas para su salud mental y física, de manera que existan ciudadanos no proactivos hacia la paz, para con su país o su región. Este propósito implica crear un grupo de competencias ciudadanas mediante las cuales cada persona adquiera la capacidad para identificar sus propias emociones, muy particularmente la ira, con el objetivo de la formación de un ente generador de paz. Miriam Jimeno, por su parte, hace referencia a varias clases de fuentes de violencia ${ }^{60}$ en el país; violencia que se encuentra reflexionada desde las conductas de la población adulta. Una de ellas el crimen pasional, el cual lo define como: "una experiencia emocional, construida y alimentada por ciertas nociones compartidas que operan en un contexto histórico y cultural. Este contexto potencia la idea moderna de la violencia como una acción loca de algunos individuos, trastornados gracias - debería poder decirse desgracias - a sus impulsos emocionales".

Si bien es imposible determinar o prever los fines y las conductas de los seres humanos, sí es presupuestable que si se educa a una persona para la paz, desde

59 Enrique Chaux, Juanita Lleras, y Ana Velásquez, "Competencias Ciudadanas: De los Estándares al Aula Una propuesta de integración a las áreas académicas”, Ediciones Uniandes, n.o 2 (2004), 127.

60 Miriam Jimeno M., “Cuerpo personal y cuerpo político. Violencia, cultura y ciudadanía neoliberal”, Universitas Humanística, n. ${ }^{\circ} 63$. (junio de 2007): 24. 
este ideal, y con todo un despliegue de la didáctica en torno a este cometido, será posible que exista una probabilidad mucho mayor de actitudes solidarias y pacíficas en el ser colombiano, pues en este sentido, valga también decir, que las prácticas dogmáticas de la escuela se constituyen en un factor generador de violencia, ya que la autoridad no proviene del conocimiento, sino de la autoridad por sí misma. Al respecto dice Quiceno ${ }^{61}$ : "Tú debes valer ante la sociedad por lo que conoces, no puedes valer ante los demás por la fuerza, por eso esta sociedad colombiana es tan violenta, porque todo nos lo imponemos por la fuerza".

En este punto es muy valioso agregar que una sociedad de conocimiento es una sociedad que tiende a ser más pacífica, y una sociedad de conocimiento es una propuesta que se halla anclada de una $u$ otra manera a la escuela, pues es este precisamente uno de los primeros lugares donde el ser humano se siente ciudadano, par, igual o común con sus semejantes. Ya en el campo del compromiso para la resolución de los conflictos por la vía de la paz, de concordancia con lo anterior, la educación para la paz:

(...) "consiste en analizar este mundo en que vivimos, pasarlo por la crítica reflexiva emanada de los valores propios de una cosmovisión pacifista y lanzar a los individuos a un compromiso transformador, liberador de las personas en tanto en cuanto que, movidas por ese análisis crítico, quedan atrapadas por la fuerza de la verdad y obligados en conciencia a cooperar en la lucha por la emancipación de todos los seres humanos y de sí mismas, en primer lugar"62.

De otro lado, valga aclarar, que para desarrollar un clima de seguridad ${ }^{63}$ y de paz en la sociedad colombiana, o al menos una aproximación a ello, se necesita que el colombiano promedio confíe en el sistema de seguridad y en las instituciones, ante problemas como el sicariato, el narcotráfico, el matoneo y el grooming ${ }^{64}$, entre otras formas de descomposición social. Por consiguiente, la escuela, como una más de las instituciones del Estado, ha de estar amparada, según Armando Márquez, bajo la protección del Estado y no desprovista del aparataje protector mismo, si bien "En las condiciones propicias, la educación brinda protección física al mejorar las condiciones de seguridad tanto para estudiantes como para profesores. En muchos conflictos, los docentes se han visto amenazados y obligados a huir, y muchas veces los estudiantes no tienen acceso a las escuelas por hallarse estas rodeadas de campos minados ${ }^{65 \prime \prime}$.

61 Humberto Quiceno, “Generación Conciencia”: Conferencia PhD. Humberto Quiceno Castrillón [Archivo de video]. Recuperado de https://www.youtube.com/watch?v=IS1AwT8c2H4 (30 de abril de 2015).

62 Martín Rodríguez, "Educar para la paz y la racionalidad comunicativa", en Educando para la paz: Nuevas propuestas, Universidad de Granada, 1994, p. 366.

Por favor verificar.

63 Soledad Granada, Jorge A. Restrepo y Andrés Vargas, "El agotamiento de la política de seguridad: evolución y transformaciones recientes en el conflicto armado colombiano", en Guerra y violencias en Colombia (Bogotá: Editorial Pontificia Universidad Javeriana, 2009), 27.

64 Se llama grooming a la acción deliberada de un adulto de acosar sexualmente a un niño o niña mediante el uso de Internet. Siempre es un adulto quien ejerce el grooming. Unicef, “Grooming, guía práctica para adultos” (Buenos Aires: con vos en la web, 2014), 2. La Educación para Todos 2000-2015: logros y desafíos 2015 (Paris: Ediciones UNESCO, 2015), 125.

65 Armando Márquez, "El papel de la educación en situaciones de posconflicto. Estrategias y recomendaciones", Hallazgos, n. ${ }^{\circ} 21$ (oc- 
Este es un punto conflictivo del país ya que el ciudadano promedio no confía en la justicia de sus instituciones veedoras del orden nacional, hecho que dificulta a la escuela el formar ciudadanos tolerantes para enfrentar realidades adversas. En este mismo plano problemático, las escuelas públicas y privadas del Estado colombiano deben encontrarse bajo el margen de la seguridad y la protección, de otra manera no es posible generar prácticas ciudadanas de paz, ya que la seguridad implica garantías para la planta física y para quienes habitan en ella. Por ello es importante que el Estado colombiano, en la misma medida en que pretenda empoderar a sus ciudadanos hacia el ideal de la paz, igualmente logre implementar políticas para la protección de las comunidades estudiantiles y sus correspondientes centros educativos, de las que no es exageración decir que son escuelas en guerra66.

\section{CONCLUSIÓN}

En términos de una educación para la paz es fundamental observar ampliamente un grupo de nuevas rutas para el conocimiento y el reconocimiento del "otro", del contexto otro, del otro pensamiento, de la diferencia, ya no en términos de fenotipo sino del pensamiento. La escuela nacional colombiana, al configurarse como uno de los primeros lugares en los que la infancia sale al encuentro del otro $^{67}$, ha de potenciar la tolerancia y la comprensión de la diferencia. También es tarea del Estado capacitar a los docentes de la república para este cometido.

De otro lado, el ideal planteado en este escrito no es de bajo costo, si bien se necesitan tiempos de clase, espacios destinados para el diálogo, recursos para asumir las actividades propuestas para la paz y, en sus primeros pasos, material didáctico producido desde las distintas disciplinas que componen los estudios multiculturales. Todo lo anterior se propone con el ánimo de desarrollar un verdadero laboratorio de paz en la escuela. Hablar de laboratorios de paz o de la comprensión de entornos multiculturales, equivale a hablar de aulas para la paz pues, si no hubiese discriminación, segregación o exclusión sociales, no habría la necesidad de crear políticas $u$ organismos desde el Estado encaminados a fortalecer la inclusión, los derechos humanos, la diversidad y la diferencia.

La escuela colombiana se halla ante la creación de dos sueños: las aulas multiculturales y las aulas de $p a z^{68}$, pero estos dos ideales no se contraponen o se interfieren; al contrario, en la medida en que uno de estos sueños se logre potencializar, contribuirá a que el otro también se concrete. La dejación de las armas con el grupo armado más grande del país se ha logrado y ahora se debe educar

tubre de 2013): 226.

66 Daniel Salgar Antolínez, "Escuelas en guerra", El Espectador, 17 de junio de 2015.

"Gobierno aún no define si va o no reforma a la Educación Superior", El Espectador, 23 de julio de 2012.

67 Entiéndase por el otro al testigo de Jehová, al gitano, al compañero de una región distinta o que posee un color distinto, y en caso de firmarse los acuerdos de La Habana, al hijo del desmovilizado.

68 Chaux, E., J. Lleras, y A. M. Velásquez. Aulas en Paz. (Bogotá: Ried Ijed, 2008), 127. 
para la paz y para armonizar la diferencia, aprendiendo a aceptar las otredades como la diversidad étnica, religiosa, política, al exparamilitar, al exguerrillero... La comprensión de los nuevos otros es un proceso extenso. No es tarde para empezar y se espera que ello sea posible.

\section{REFERENCIAS}

Aristizábal, Magnolia, María Eugenia Muñoz y Carlos Tosse. “El gigante en el país de los liliputienses: Las ilusiones del desarrollo y el planeamiento para la educación", en Traslapamiento de la pedagogía por el currículo: Colombia 1960-1975, compilado por M. Aristizábal, 47. Popayán: Editorial Universidad del Cauca, 2011.

Ávila, Ariel. “Los 50 años de guerra podrían ser el último cumpleaños”, Semana, n. 1778 (mayo de 2014).

Bernand, Carmen. "Identificaciones: músicas mestizas, músicas populares y contracultura en América (siglos XvI-XIx)", Historia Crítica, n. ${ }^{\circ} 54$ (2014): 22.

Bolaños, José. “La educación en Colombia. Una mirada al tiempo, espacio y pensamiento curricular desde las guías didácticas para maestros de escuela primaria en Colombia", en Traslapamiento de la pedagogía por el currículo: Colombia 1960-1975, compilado por Magnolia Aristizábal, 171. Popayán: Editorial Universidad del Cauca, 2011.

Castro, Santiago. "Ciencias sociales, violencia epistémica y el problema de la invención del otro", en La colonialidad del saber: eurocentrismo y ciencias sociales. Perspectivas latinoamericanas, 91. Buenos Aires: Consejo Latinoamericano de Ciencias Sociales (ClACso), 2000.

Castillo, E. y Axel Rojas, E. Educar a los otros. Estado, políticas educativas y diferencia cultural en Colombia. Popayán: Editorial Universidad del Cauca, 2005.

Chaux, Enrique. "Buscando pistas para prevenir la violencia urbana en Colombia: conflictos y agresión entre niños(as) y adolescentes en Bogotá", Revista de Estudios Sociales, n. ${ }^{\circ} 12$ (2002): 43.

Chaux, E., J. Lleras, y A. M. Velásquez. Aulas en Paz. (Bogotá: Ried Ijed, 2008), 127.

Colmenares, Germán. Historia económica y social de Colombia. Bogotá: Instituto Nacional de Cultura, 1979.

Cortina, Adela. Ciudadanos del mundo. Hacia una teoría de la ciudadanía. Madrid: Alianza Editorial, 2009.

Díaz, Ernesto. “Multiculturalismo y educación”. Cultura y representaciones sociales, n. 7 (2009), 3144-50.

Duarte, Jorge y Riveros, Martha. “El Uso del Catecismo en la Enseñanza de la Religión Católica en el Periodo Neogranadino y de los Estados Unidos de Colombia 1831-1886", Revista Historia de la Educación. no. 16 (2011): 126.

Dubet, François. Repensar la justicia social. Contra el mito de la igualdad de oportunidades. Madrid: Siglo xxI editores, 2010.

Fayad, Jaime. "Del planeamiento educativo al currículum, un pensamiento imperial", en Traslapamiento de la pedagogía por el currículo: Colombia 1960-1975, compilado por Magnolia Aristizábal, 48. Popayán: Editorial Universidad del Cauca, 2011.

Geertz, Clifford. Los usos de la diversidad. Barcelona: Ediciones Paidós, 1996.

Goffman, Erving. Estigma. La identidad deteriorada. Madrid: Amorrortu Editores, 2006.

Gómez, Ana. Pueblo Rrom - Gitano - de Colombia: haciendo camino al andar. Bogotá: Departamento Nacional de Planeación (DNP), 2010.

Granada, Soledad, J. A. Restrepo y Andrés Vargas. “El agotamiento de la política de seguridad: evolución y transformaciones recientes en el conflicto armado colombiano", en Guerra y violencias en Colombia. Bogotá: Editorial Pontificia Universidad Javeriana, 2009.

Grueso, Delfín. “Qué es el multiculturalismo?”, El Hombre y la Máquina, n. o 20-21 (2003): 17. 
Herrera, Mónica. “Los retos del Estado multicultural en materia de paz”. Semana, n. 1777 (junio, 2013).

Jacquard, Albert. “Multiculturalidad". Olympus, n. ${ }^{\circ}$ (2003): 2.

Jimeno, Miriam. "Cuerpo personal y cuerpo político. Violencia, cultura y ciudadanía neoliberal”. Universitas Humanística, n. 63 (2007).

Marco, Aurora. "Multiculturalismo y educación". Puertas a la lectura, n. ${ }^{\circ}$ 9-10 (2000): 3.

Márquez, Armando. "El papel de la educación en situaciones de posconflicto: Estrategias y recomendaciones". Hallazgos, n. ${ }^{\circ} 21$ (2013): 226.

Martínez, Alberto. Dos estudios sobre la educación en la Colonia. Bogotá: Universidad Pedagógica Nacional (CIUP), 1984.

Martínez, Alberto. “De la escuela expansiva a la escuela competitiva: dos modos de modernización en América Latina". Reseñas Educativas, n. ${ }^{\circ} 90$ (2005): 4.

Maturana, Humberto, Fernando Coddou, Hernán Montenegro, Gloria Kunstmann y Carmen Luz Méndez. Violencia. En sus distintos ámbitos de expresión. Santiago: Dolmen Mundo Abierto, 2000.

Nieto, Danilo. La educación en el Nuevo Reino de Granada (Bogotá: Ediciones Santa Fe, 1955), 74.

Mockus, Antanas. “¿Para qué el perdón?”. Theologica Xaveriana, n. 141 (2002): 47-60.

Moreno, Héctor. "Estado multicultural y derechos diferenciados en Colombia". Criterio Libre Jurídico, 8, n. ${ }^{\circ} 1$ (2011): 10.

Poblete, Rolando. "Multiculturalismo y educación". Revista latinoamericana de educación inclusiva, n. ${ }^{\circ} 3$ (2005): 184.

Quiceno, Humberto. Generación Conciencia: Conferencia PhD. Humberto Quiceno Castrillón [Archivo de video]. Recuperado de: https://www.youtube.com/watch?v=IS1AwT8c2H4 (30 de abril de 2015).

Rangel, Jorge “Etnización en La Boquilla (Cartagena - Colombia) Bogotá: Pontificia Universidad Javeriana., 2015.

Restrepo, Eduardo. “Etnización de la Negridad", en Genealogías de la colombianidad, 96. Bogotá: Editorial Pontificia Universidad Javeriana, 2008.

Rodríguez, Martín. "Educar para la paz y la racionalidad comunicativa", en Educando para la paz: Nuevas propuestas, 366. España: Universidad de Granada, 1994.

Sáez, Rafael. “La educación intercultural”. Revista de Educación, n. 339 (2006): 859.

Saldarriaga, Oscar. Del oficio del maestro. Prácticas y teorías de la pedagogía moderna en Colombia. Bogotá: Cooperativa Editorial Magisterio, 2003.

Salgar, Daniel. “Escuelas en guerra”. El Espectador, 17 de junio de 2015.

Soto, Diana. Rivadeneira, José. Duarte, Jorge. Bernal, Sandra, “La generación del movimiento estudiantil en Colombia. 1910-19241", Revista Historia de la Educación Vol. 20 no. 30 (2018): 225.

Taylor, Charles. El multiculturalismo y "la política del reconocimiento". Ciudad de México: Fondo de Cultura Económica, 2010.

Timaná, Queipo. “iPor qué y sobre qué debemos investigar en pedagogía en Colombia?”. Praxis y Saber, n. ${ }^{\circ} 1$ (2009): 252.

Tuvilla, José. "Cultura de paz y educación para la ciudadanía democrática" (jornadas de cooperación educativa con Iberoamérica sobre educación y cultura para la paz, Cartagena, 20 al 24 de noviembre de 2006). Recuperado de: http://www.aecidcf.org.co/documentos/MI\%20 11.669.pdf

Unesco. “La educación para todos, 2000-2015: logros y desafíos". París: Ediciones Unesco, 2015.

Unicef. "Grooming, guía práctica para adultos". Buenos Aires, Argentina: con vos en la web, 2014.

Unda, María y Gutiérrez, Alba. “Viajes y encuentros pedagógicos como experiencias de formación de maestros" Nodos y Nudos. Volumen 4 N. ㅇ 39. (2015): 9.

Wacquant, Loïc. Parias urbanos. Marginalidad en la ciudad a comienzos de milenio. Buenos Aires: Manantial, 2001.

Walsh, Catherine, ed. Pedagogías decoloniales. Prácticas insurgentes de resistir, (re)existir y (re)vivir. Qui- 
to: Abya-Yala, 2013.

Walsh, Catherine. La Interculturalidad en la Educación. Lima: Ministerio de Educación / Unicef, 2005. Zuleta, Estanislao. Colombia: violencia, democracia y derechos humanos. Bogotá: Ariel, 2015.

Zapata Olivella, Manuel. Changó, el Gran Putas. Bogotá: Ministerio de Cultura de Colombia, 2010.

\begin{tabular}{l|l} 
& \\
\hline Cómo citar: & \\
Bolaños Motta, José Ignacio. “Aulas multiculturales y aulas de \\
paz. Dos propuestas para un país en posconflicto" Revista Historia \\
de la Educación Latinoamericana. Vol. 20 No. 31 (2018): 83-100 \\
DOI: 10.19053/01227238.8563
\end{tabular}

